\section{Simulated Transport, Postproduction Irradiance Influence Postproduction Performance of Potted Roses}

\author{
Terril A. Nell \\ Environmental Horticulture Department, University of Florida, \\ Gainesville, FL 32611

\section{Cor Vonk Noordegraaf \\ Proefstation Voor de Bloemisterij, Aalsmeer, The Netherlands}

Additional index words postharvest, longevity, light, shipping, miniature rose, Rosa sp

Abstract. Three simulated transport temperatures $(5,11$, or 17C) and durations. (3, 6, or 9 days) were used to evaluate the postproduction flowering patterns of miniature potted rose (Rosa sp) 'Orange Rosamini'. The postproduction environment was maintained at $20 \pm 1 \mathrm{IC}, 60 \% \pm 5 \%$ relative humidity (RI-I), and an irradiance level, from cool-white fluorescent lamps, of $4.5 \mathrm{~W} \cdot \mathrm{m}^{-2}$ photosynthetically active radiation (PAR) for 12 hours daily to simulate conditions at the retail or consumer level. At 3 weeks postproduction, plants held for 9 days at $17 \mathrm{C}$ had the fewest buds showing color per plant. As temperature increased, there were fewer flowers per plant at weeks 2 and 3 of postproduction. In a second study, the effect of simulated transport ( 3 days at $5 \mathrm{C}$ vs. no transport) and postproduction irradiance level $\left(1,2\right.$, or $\left.4 \mathrm{~W} \cdot \mathrm{m}^{-2} \mathrm{PAR}\right)$ were evaluated over a 7-week postproduction period for 'Orange Rosamini'. A three-way interaction was observed between simulated transport treatment, postproduction irradiance level, and time in postproduction for the number of open flowers per plant. Plants responded similarly at 1 and $2 \mathrm{~W} \cdot \mathrm{m}^{-2}$ throughout the postproduction period, regardless of transport treatment; however, at $4 \mathrm{~W} \cdot \mathrm{m}-2$ the plants of the no transport treatment had two to three open flowers each week up to week 6 of postproduction, while plants subjected to simulated transport followed the pattern of one and two open flowers for 0 to 3 weeks. Flowering then increased to three to four open flowers for the duration of the postproduction period. A third study involved two simulated transport treatments (3 days at SC vs. no transport), three postproduction irradiance levels $\left(1,2\right.$, and $4 \mathrm{~W} \cdot \mathrm{m}^{-2} \mathrm{PAR}$ ), and six miniature rose cultivars ('Orange Rosamini', 'Red Minimo' 'Sweet Rosamini', 'Golden Rosamini', 'Favorite Rosamini', and 'White Rosamini'). Plants held at 1 or $2 \mathrm{~W} \cdot \mathrm{m}^{-2}$ for 3 weeks had no open flowers, while those held at $4 \mathrm{~W} \cdot \mathrm{m}^{-2}$ for 3 weeks had one to four open flowers, except 'Sweet Rosamini', which had no open flowers with simulated transport.
Environmental conditions affect the quality and longevity of flowering potted plants and cut flowers (Halevy and Mayak, 1981; Nell and Barrett, 1990). Although considerable research has been done on the effects of production irradiance levels on potted plants, no studies have demonstrated the effects of very low postproduction irradiance levels [ $<5 \mathrm{~W} \cdot \mathrm{m}^{-2}$ photosynthetically active radiation (PAR)] on the postproduction flowering performance of potted rose.

High temperature, darkness, and ethylene can result in leaf yellowing, leaf abscission, and bud drop in flowering potted plants (Nell

Received for publication 3 Aug. 1990. Florida Agr J. Ser. no. R-00202. We are grateful to American Floral Endowment and the D.C. Kiplinger Chair in Floriculture for support of this project, Pouw Rosen for the plants used in these studies, Tanja Rosendal-Ouwerkerk and Lori A. Black for technical assistance, and Ramon C. Littell for assistance in statistical analysis. The cost of publishing this paper was defrayed in part by the payment of page charges. Under postal regulations, this paper therefore must be hereby marked advertisement solely to indicate this fact. transport periods between 5 and 20C have not been investigated.

The objective of this research was to determine the effects of simulated transport (ST) temperature and duration, postproduction irradiance level ( 1 to $4.5 \mathrm{~W} \cdot \mathrm{m}^{-2} \mathrm{PAR}$ ), and cultivar on the flowering performance of potted miniature roses over a postproduction period.

Experimental procedure. Three experiments were conducted on flowering potted miniature roses, crown diameter of 14 to 16 $\mathrm{cm}$, planted in 10-cm (1.1 liters) pots. All plants were received from a commercial grower and placed directly under ST or postproduction conditions. Transport was simulated by placing nonsleeved plants into closed boxes. Postproduction evaluations were conducted in environmental control rooms maintained at $20 \pm 1 \mathrm{C}, 60 \% \pm 5 \%$ relative humidity (RI-I), and irradiance levels, from cool-white fluorescent lamps, of 1 to 4.5 $\mathrm{W} \cdot \mathrm{m}^{-2} \mathrm{PAR}$ (depending on experiment) for $12 \mathrm{~h}$ daily to simulate conditions at the retail or consumer level. Irradiance levels were determined using a pyranometer (LI-COR model LI 200SA Pyranometer Sensor; LI-COR, Lincoln, Neb.) to measure PAR at plant level. Plants were watered, without fertilizer, as needed throughout the postproduction period. Unless stated otherwise, evaluation of postproduction performance was based on the number of buds showing color and open flowers per plant. These data were recorded before initiation of treatments, at unboxing, and after each week under postproduction conditions. Data were tested by analysis of variance, analysis of covariance, and $\mathrm{Tu}$ key's honestly significant difference (HSD) test.

ST temperature and duration. A factorial experiment was established using three ST temperatures $(5,11$, or $17 \mathrm{C})$ and three durations $(3,6$, or 9 days). A control treatment, i.e., plants placed directly into postproduction without ST, was included. 'Orange Rosamini' plants were removed from ST and placed in postproduction conditions providing $4.5 \mathrm{~W} \cdot \mathrm{m}^{-2}$ for 3 weeks. The design was a randomized complete block with six replications and two plants per experimental unit.

The number of buds showing color was different only between control and treated plants at week 1 (data not shown). No significant difference was observed at unboxing or week 2 (data not shown), but there was
Table 1. Repeated measures analysis of variance done on the square-root transformations of the number of buds showing color per plant for 'Orange Rosamini' miniature rose.

\begin{tabular}{lrrrr}
\hline \hline Source & df & MS & F & $P>F^{z}$ \\
\hline Irradiance & 1 & 8.742 & 39.51 & 0.0001 \\
Transport & 1 & 0.751 & 3.39 & 0.0706 \\
Irradiance $\times$ transport & 1 & 1.064 & 4.81 & 0.0323 \\
Error & 58 & 0.221 & & \\
Time & 7 & 3.711 & 18.02 & 0.0001 \\
Time $\times$ irradiance & 7 & 0.834 & 4.05 & 0.0016 \\
Time $\times$ transport & 7 & 0.128 & 0.62 & 0.6794 \\
Time $\times$ irradiance $\times$ transport & 7 & 0.288 & 1.40 & 0.2033 \\
Error (time) & 406 & 0.206 & & \\
\hline
\end{tabular}

${ }^{x}$ Greenhouse-Geisser-adjusted $P$ values are reported for time effects. 

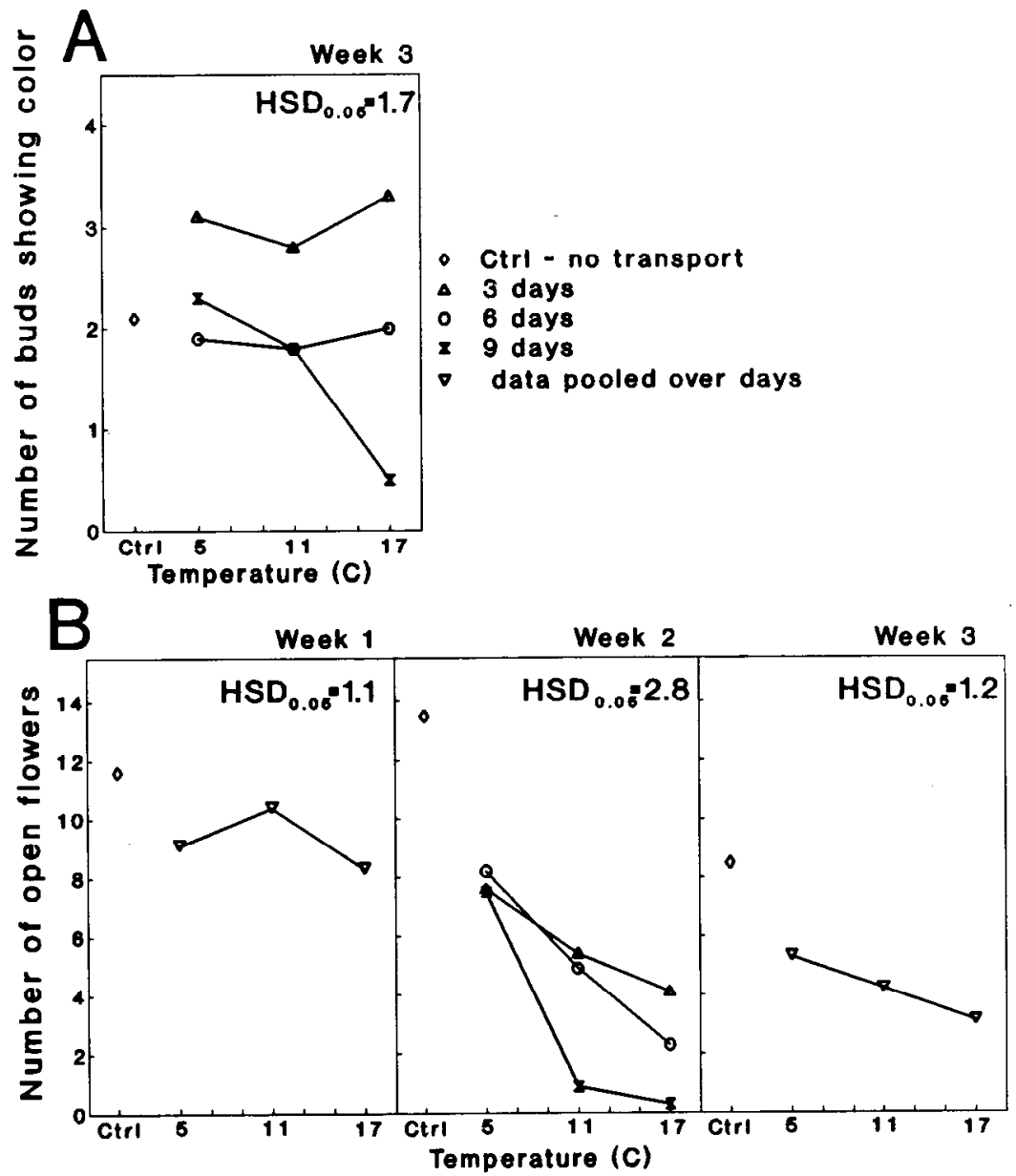

Fig. 1. Effect of simulated transport temperature and duration on the number of buds showing color per plant (A) and the number of open flowers per plant (B) for 'Orange Rosamini' miniature rose placed in postproduction conditions ( 3 weeks at $20 \pm 1 \mathrm{C}$ and $60 \% \pm 5 \%$ relative humidity with $4.5 \mathrm{~W} \cdot \mathrm{m}^{-2}$ of irradiance for $12 \mathrm{~h}$ daily). Interaction significant for buds showing color (week 3 ) and open flowers (week 2) at $P=0.05$ and 0.01 , respectively. Simulated transport duration and interaction nonsignificant for number of open flowers at weeks 1 and 3; therefore, data pooled over days. HSDS do not include controls.

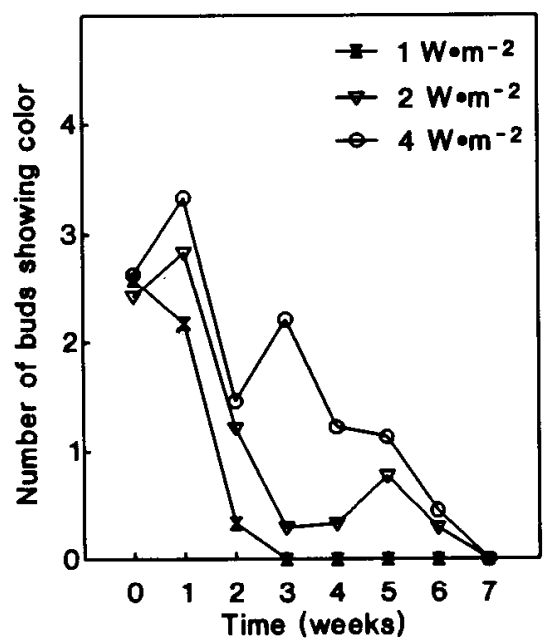

Fig. 2. Effect of postproduction irradiance level (constant $20 \pm 1 \mathrm{C}$ and $60 \% \pm 5 \%$ relative humidity with $12 \mathrm{~h}$ of irradiance daily) over time on the number of buds showing color per plant for 'Orange Rosamini' miniature rose in postproduction. Points are means of 24 plants. Interaction between time and irradiance significant at $P=0.0008$.
1, plants held at $11 \mathrm{C}$ had the most open flowers. At week 2, plants held for 3 or 6 days had fewer open flowers as temperature increased, while those held for 9 days had seven open flowers at $5 \mathrm{C}$ and only zero to one open flower at 11 or $17 \mathrm{C}$. At week 3, the number of open flowers was less the higher the temperature. Control plants (no transport) had more open flowers than treatment plants at weeks 2 and 3. For all treatments, buds that were not showing color at the beginning of the experiment continued to develop during the first week of postproduction, as evidenced by an increasing number of open flowers and the failure of buds showing color to abscise during the first week.

ST and postproduction irradiance over time. A factorial experiment was established using ST (3 days at 5C) vs. no ST and three postproduction Irradiance levels $(1,2$, or 4 $\left.\mathrm{W} \cdot \mathrm{m}^{-2}\right)$. 'Orange Rosamini' plants were evaluated with repeated-measures analysis of variance over a 7-week postproduction period. Data also included number of petals per flower and flower diameter for 12 plants (one sample per plant) in the no ST treatment at each postproduction irradiance level. Buds showing color were tagged on days 0,3 , and 7 of postproduction for determination of petal number per flower and flower diameter when flowers were fully open. The experiment was in a completely randomized design with 12 plants per experimental unit.

Throughout the 7-week postproduction period there was a two-way interaction between time and irradiance level for the number of buds showing color per plant (Table 1; Fig. 2). Plants held at 1 or $2 \mathrm{~W} \cdot \mathrm{m}^{-2}$ had a similar pattern, with two to three buds showing color from week 0 to 1 and then zero to one bud showing color from weeks 2 to 7 . However, plants held at $4 \mathrm{~W} \cdot \mathrm{m}^{-2}$ had one to three-buds showing color from weeks 0 to 5 and then decreased to below one bud showing color from week 6 to 7 . ST had a minimal effect on the number of buds showing color (Table 1).

There was a three-way interaction between transport treatment, irradiance level, and time in ST for the number of open flowers per plant (Table 2; Fig. 3). The effects of 1 and $2 \mathrm{~W} \cdot \mathrm{m}^{-2}$ were similar for no transport and transport treatments, with two to three open flowers at week 1 and then zero to one open flower after week 2 . The interaction was due to the response at $4 \mathrm{~W} \cdot \mathrm{m}^{-2}$,

Table 2. Repeated measures analysis of variance done on the square-root transformations of the number of open flowers per plant for 'Orange Rosamini' miniature rose.

\begin{tabular}{lrrrr}
\hline \hline Source & df & \multicolumn{1}{c}{ MS } & F & $P>F^{2}$ \\
\hline Irradiance & 1 & 31.923 & 99.17 & 0.0001 \\
Transport & 1 & 0.546 & 1.70 & 0.1979 \\
Irradiance $\times$ transport & 1 & 0.012 & 0.04 & 0.8495 \\
Error & 58 & 18.671 & & \\
Time & 7 & 5.180 & 24.18 & 0.0001 \\
Time $\times$ irradiance & 7 & 2.233 & 10.42 & 0.0001 \\
Time $\times$ transport & 7 & 0.491 & 2.29 & 0.0492 \\
Time $\times$ irradiance $\times$ transport & 7 & 1.274 & 5.59 & 0.0001 \\
Error (time) & 406 & 0.214 & & \\
\hline
\end{tabular}

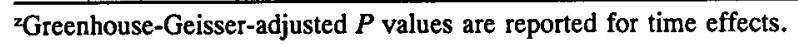




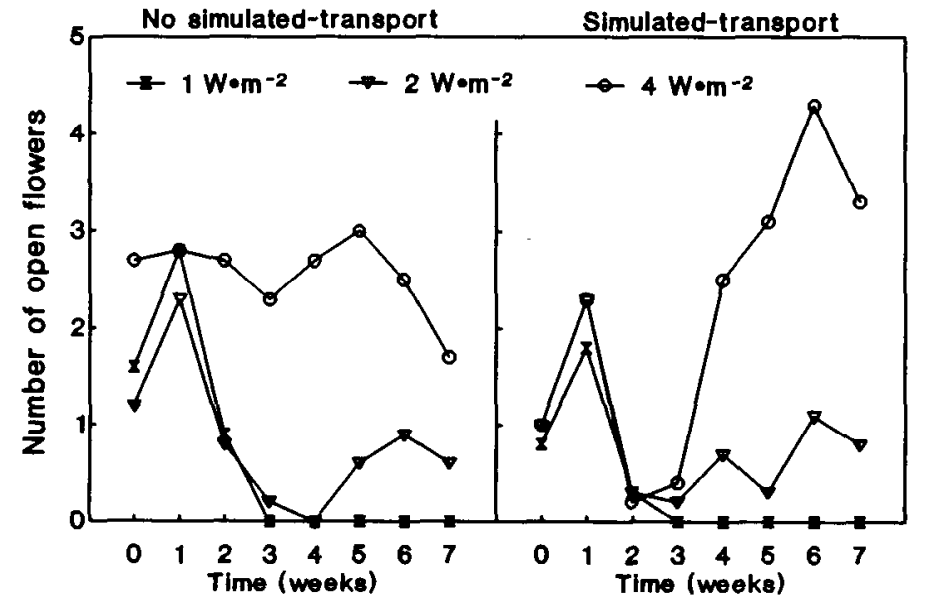

Fig. 3. Effect of simulated transport ( 3 days at SC in closed boxes without sleeves) and postproduction irradiance level (constant $20 \pm 1 \mathrm{C}$ and $60 \% \pm 5 \%$ relative humidity with $12 \mathrm{~h}$ of irradiance daily) over time in postproduction on the number of open flowers per plant for 'Orange Rosamini' miniature rose in postproduction. Points are means of 12 plants. Interaction between simulated transport, irradiance, and time significant at $P=0.0001$.

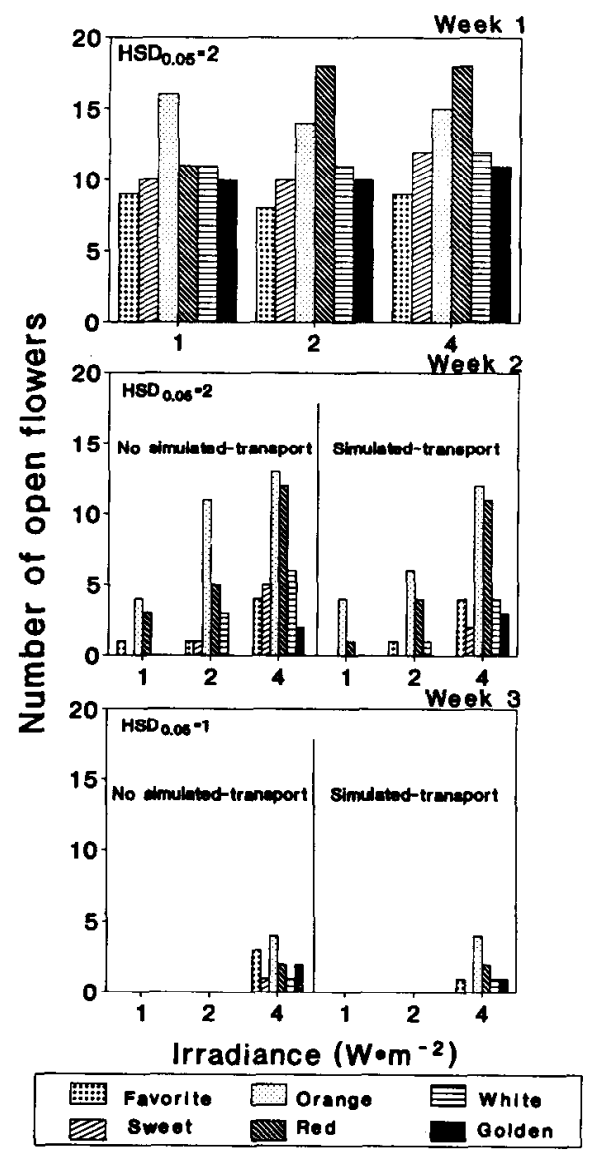

Fig. 4. Effect of simulated transport, postpro-' duction irradiance level, and cultivar ('Orange Rosamini', 'Red Minimo', 'Sweet Rosamini', 'Golden Rosamini', 'Favorite Rosamini', and 'White Rosamini') on the number of open flowers per plant at weeks 1,2 , and 3 of postproduction $(20 \pm 1 \mathrm{C}$ and $60 \% \pm 5 \%$ relative humidity with 1,2 , or $4 \mathrm{~W} \cdot \mathrm{m}^{-2}$ of irradiance for $12 \mathrm{~h}$ daily). A two-way interaction (irradiance $\mathrm{x}$ cultivar) was significant at $P=0.05$ for week 1 , and the three-way interaction was significant at $P=0.01$ for weeks 2 and 3 .

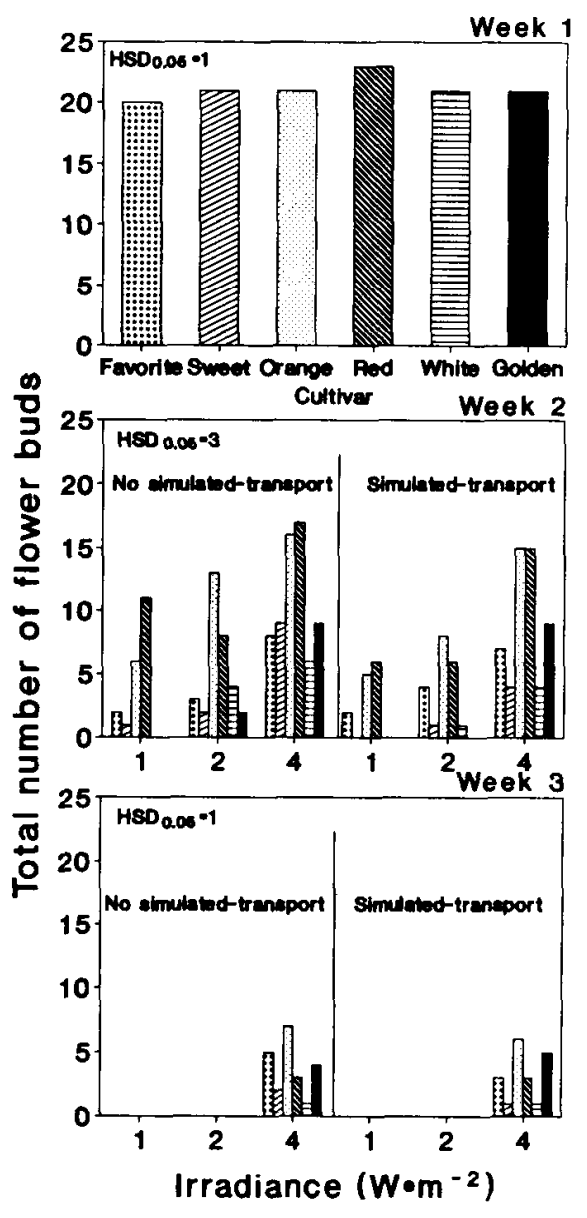

Fig. 5. Effect of simulated transport, postproduction irradiance, and cultivar ('Orange Rosamini', 'Red Minimo', 'Sweet Rosamini', 'Golden Rosamini', 'Favorite Rosamini', and 'White Rosamini') on the total number of flower buds (open flowers, buds showing color, and green buds) per plant at weeks 1,2 , and 3 of postproduction $(20 \pm 1 \mathrm{C}$ and $60 \% \pm 5 \%$ relative humidity with 1,2 , or $4 \mathrm{~W} \cdot \mathrm{m}^{-2}$ of irradiance for $12 \mathrm{~h}$ daily). The effect of cultivar was significant at $P=0.01$ for week 1 , and the three-way interaction was significant at $P$ $=0.01$ for weeks 2 and 3 . where the plants without ST had two to three open flowers each week to week 6 , while plants with ST followed a pattern of one and two open flowers for 0 to 3 weeks. Flowering then increased to three to four open flowers for the duration of the postproduction period.

Flower diameter was smaller at $1 \mathrm{~W} \cdot \mathrm{m}^{-2}$ than at $4 \mathrm{~W} \cdot \mathrm{m}^{-2}$; however, petal number was not affected by postproduction irradiance level (data not shown).

$S T$, postproduction irradiance, and miniature rose cultivar. A $2 \times 3 \times 6$ factorial experiment was established using ST (3 days at $5 \mathrm{C}$ ) vs. no ST, three postproduction irradiance levels $\left(1,2\right.$, or $\left.4 \mathrm{~W} \cdot \mathrm{m}^{-2}\right)$, and six cultivars ('Orange Rosamini', 'Red Minimo', 'Sweet Rosamini', 'Golden Rosamini', 'Favorite Rosamini', and 'White Rosamini'). The total number of flower buds (green buds, buds showing color, and open flowers) per plant was also recorded after each week in postproduction to determine postproduction flowering potential. Postproduction performance was evaluated for 3 weeks. The design was a randomized complete block with six replications and two plants per experimental unit.

For the number of open flowers per plant at week 1, there was a two-way interaction between irradiance level and cultivar, while week 2 and 3 exhibited significant three-way interactions (Fig. 4). At week 1, 'Favorite Rosamini', 'Sweet Rosamini', White Rosamini', and 'Golden Rosamini' had a similar number of open flowers at each irradiance level. However, 'Orange Rosamini' had more open flowers at $1 \mathrm{~W} \cdot \mathrm{m}^{-2}$ than at $2 \mathrm{~W} \cdot \mathrm{m}^{-2}$, and 'Red Minimo' had the most open flowers at 2 and $4 \mathrm{~W} \cdot \mathrm{m}^{-2}$. At week 2, most cultivars (except for 'Favorite Rosamini' and 'Orange Rosamini' at 1 or $4 \mathrm{~W} \cdot \mathrm{m}^{-2}$ ) had more open flowers in the no transport treatment. There were more open flowers at 4 $\mathrm{W} \cdot \mathrm{m}^{-2}$ than at 1 or $2 \mathrm{~W} \cdot \mathrm{m}^{-2}$ for both transport treatments and all cultivars. At week 3, the sensitivity of all cultivars to low irradiance levels was apparent; no cultivars had open flowers at 1 or $2 \mathrm{~W} \cdot \mathrm{m}^{-2}$. 'Favorite Rosamini', 'Sweet Rosamini', and 'Golden Rosamini' without ST had more open flowers at $4 \mathrm{~W} \cdot \mathrm{m}^{-2}$ than those with $\mathrm{ST}$; however, transport treatment did not affect the number of open flowers at $4 \mathrm{~W} \cdot \mathrm{m}^{-2}$ for 'Orange Rosamini', 'Red Minimo', and 'White Rosamini'.

The total number of flower buds per plant was only significantly different at week 1 due to cultivar, and there was a significant three-way interaction at weeks 2 and 3 (Fig. 5 ). At week 2, all cultivars showed a higher total number of buds at $4 \mathrm{~W} \cdot \mathrm{m}^{-2}$ than at 1 or $2 \mathrm{~W} \cdot \mathrm{m}^{-2}$. However, cultivars differed in response to transport treatment and effect of 1 vs. $2 \mathrm{~W} \cdot \mathrm{m}^{-2}$. At week 3 , no cultivar had any flower buds at 1 or $2 \mathrm{~W} \cdot \mathrm{m}^{-2}$, regardless of transport treatment. The total number of buds was higher at $4 \mathrm{~W} \cdot \mathrm{m}^{-2}$ for 'Favorite Rosamini', 'Sweet Rosamini', and 'Orange Rosamini' without ST. All other cultivars had a similar total number of buds at 4 $\mathrm{W} \cdot \mathrm{m}^{-2}$, regardless of transport treatment. 
Differences in the number of open flowers at weeks 2 or 3 of postproduction were due to senescence and abscission of either green buds or buds showing color. The timing of bud abortion depended on cultivar. Sepals began to yellow within 1 week on 'Favorite Rosamini' and 'Golden Rosamini' at 1 $\mathrm{W} \cdot \mathrm{m}^{-2}$, whereas yellowing was detected on days 8 to 12 for the other cultivars (data not shown). Senescence was associated with a wilting of the expanded petals in 'Favorite Rosamini', while petiole curving and sepal yellowing were common in 'Golden Rosamini', 'Pink Rosamini', and 'Orange Rosamini'. Sepal yellowing was not observed in 'Favorite Rosamini'.

Our results demonstrate that transport can be extended to 9 days for 'Orange Rosamini' provided that temperature is maintained at $\sim 5 \mathrm{C}$. These data also indicate that 'Favorite Rosamini', 'Sweet Rosamini', and 'Golden Rosamini' are the most sensitive to transport. Detrimental effects of transport (3 days at SC) were overcome with an irradiance level of $4 \mathrm{~W} \cdot \mathrm{m}^{-2}$ by week 4 of postproduction for 'Orange Rosamini'. Optimal postproduction irradiance was $4 \mathrm{~W} \cdot \mathrm{m}^{-2}$, regardless of transport treatment.

We observed bud abscission at week 2 of postproduction under low-irradiance conditions. At week 2, some developing shoots had characteristics similar to blind shoots on cut roses. It is conceivable that two separate senescence systems occur in potted rose: shoot abortion during the first 2 to 3 weeks of postproduction and blindness afterwards. Yel- lowing of sepals and curvature of the stem subtending the inflorescence was observed before abscission in most of the cultivars evaluated. Further work is needed to identify the physiological basis for flower bud abortion under postproduction conditions.

\section{Literature Cited}

Halevy, A.H. and A.H. Kofranek. 1976. The prevention of flower bud and leaf abscission in pot roses during simulated transport. J. Amer. Soc. Hort. Sci. 101:658-660.

Halevy, A..H. and S. Mayak. 1981. Senescence and postharvest physiology of cut flowers-Part 2, p. 59-143. In: J. Janick (ed.). Horticultural review. vol. 3. AVI, Westport, Conn.

Nell. T.A. and J.E. Barrett. 1990. Post-production handling of bedding and potted plants. Acta Hort. 272:311-317. 